graphic records of all the elements. One occurred between 10.30 and 11.25 p.m. on the declination, the magnet swinging east, and the range being $3^{8}$. This was preceded at 11.5 p.m. by an increase of H.F. of $3^{\prime}$. A second peak was recorded on this element at I.45 a.m. on June 18 , the force decreasing by $\mathrm{II}^{\prime}$. A small decrease of V.F. accompanied this movement of the H.F.

The sun's surface, though disturbed, had been almost free from spots between June 5 -II. But from June I2, when a group of spots appeared in bright faculæ at the east limit, and almost on the sun's equator, the solar surface became very active with spots, bright faculæ, pores, and drifts of granulations. Individually the spots were not very large, but on June $I 7-18$ there were no fewer than seven groups of spots visible, all displaying considerable changes of form. In particular there were two sympathetic groups, one, already referred to, extending in latitude from $+\mathrm{I} \cdot 5^{\circ}$ to $+4^{\circ}$, and in mean longitude $35^{\circ}$, and the other in latitude $-17^{\circ}$ and longitude $46^{\circ}$. The whole region of the sun between these two groups was very active, the faculæ being visible even at the centre of the disc, with streams of granulations connecting the two groups. On June I7 the southern group passed the central meridian, and the northern group on June 18 . The heliographic latitude of this northern group was almost exactly that of the earth as projected on the sun, so that on June 18 the spot group and the earth were radially opposite one another. Such a close approximation of the position of the spot and the earth referred to the sun's central meridian during a magnetic storm is very unusual. It certainly has not occurred in any violent magnetic storm since the year 1898 .

Stonyhurst College Observatory, June 20.

\section{Man's True Thermal Environment}

Following Dr. Hill's article on healthy atmospheres in NATURE of April 22, a letter appeared in NATURE of May 6 under the above heading, which suggests that too narrow a view has been taken of this important subject. Dr. Milne writes from a place where man exists in spite of the climate, and no doubt the robustness of the local race is largely due to generations of selection under rigorous conditions that are only overcome with the aid of ponderous clothing and heated dwellings. At the outset we should inquire as to the thermal conditions that existed at the birth of our race. No doubt man soon learnt to keep himself warm by artificial means, but he appeared first in association with a fauna almost tropical in character. It is in tropical regions that our race exists to-day in comfort with little or no protection and in spite of many adverse organisms that are also favourcd by warmth.

What results would Dr. Milne's psuchrainometer give us in these places? For it is of importance if figures of any value are to be, obtained that the methods should be generally applicable to habitable regions. It is not remarkable that methods bred in an extreme climate must fail in quite congenial regions but where the air temperature is often over $38^{\circ} \mathrm{C}$. and sometimes exceeds $45^{\circ} \mathrm{C}$. Here, no doubt, Dr. Milne's ingenuity would produce a metapsuchrainometer to tell us what heat must be taken from a body to keep it at blood-heat. We should be the richer for a valuable device, but our knowledge of man's true environment would not be much advanced.

Meteorologists have succeeded very well in obscuring the significance of the wet-bulb temperatures by wrapping them up in terms of relative humidity, The relation of the dry- and wet-bulb reading, besides giving us the potential cooling power of the atmosphere as it affects a moist surface, enables us to arrive at the absolute humidity and the specific heat of the air. This last factor no doubt varies considerably with the moisture content, and must be of importance in the convection affecting the heated body of the psuchrainometer.

Dr. Milne's $\psi$ only takes into account the air temperature, specific heat and velocity, provided radiation effects are constant. It cannot be taken to represent the whole environmental effect, which depends also on the power of the air to take up moisture. The katathermometer figures appear most promising in this respect, but the present form of instrument is probably not completely suitable for hot climates.

Khartoum, May 26.

G. W. Grabham.

\section{A Continuous Spectrum in the Ultra-Violet.}

The following observation may be of interest in connection with Prof. E. P. Lewis's letter in Nature of June io.

During some recent experiments which I carried out in the Cavendish Laboratory, it was observed that the radiation coming from the gas in the path of the discharge between a Wehnelt kathode and an iron anode was rich in ultra-violet light. The strength of the discharge current was between one and two amperes. With air in the bulb and the pressure reduced as low as possible with a Geryk pump, the spectrum, which was photographed with a small Hilger quartz spectrograph, showed the nitrogen bands and the mercury line $\lambda 2536$. As the pressure was increased by admitting a small quantity of hydrogen a continuous spectrum made its appearance, the mercury line increasing in intensity relatively to the bands. By washing out the bulb several times with hydrogen and removing the air by means of charcoal and liquid air, a continuous spectrum was obtained which showed no signs of the bands and lines. The spectrum extended beyond $\lambda 2000$ and gradually faded away, due to the absorption in the spectrograph. The pressure of the hydrogen in the bulb was about $2 \mathrm{~mm}$.

It is thought that this continuous spectrum is the result of the bombardment of the hydrogen molecules by slow-moving electrons, the energy of which is not sufficient to produce ionisation in hydrogen. Further experiments are necessary to test this idea, and I hope to be able to carry them out on my return to Inerica.

The University, Manchester, June 19.

\section{The Names of Physical Units.}

To all who are interested in the improvement of scientific nomenclature the points raised by Dr. Guillaume's letter (Nature, June I7, p. 42 7 ) are of great importance. In my opinion the case for rational nomenclature has been stated with both logic and humour by Dr. Guillaume, while Dr. Harker's reply seems to show misapprehension of the main point. All good nomenclature should be unambiguous, and, if possible, self-explanatory. The terms masse volumique, volume massique, and stéradian have both these desirable qualities; no one with a knowledge of physics and French could make any mistake as to the exact meaning of the first two, and the meaning of the third should be at once self-evident to anyone who knows the definition of a solid angle. I should not expect a chemist or a botanist to have anything but a hazy idea of the meaning of puissance massique, but even to an ordinary French engineer it should convey its meaning instantly.

NO. 2382 , VOL. 95] 